\title{
Organizational Control Structure
}

\author{
A General Descriptive Technique as applied to \\ Four Local Unions ${ }^{1}$
}

ARNOLD S. TANNENBAUM AND ROBERT L. KAHN

MUCH interest of late has been focused on the importance of the control function in organizations. Cartwright has pointed out that 'a major deficiency of our theories of group psychology and of social psychology generally is that we have been soft on power', and he has reviewed a number of studies that demonstrate the importance of this variable in interpersonal situations(1). Some effects of varying conditions of control within an organization have been discussed by Worthy, who points out that delegation of control to local autonomous groups within a large organization has a favorable effect on morale (8). A recent experiment performed by the Human Relations Program of the Survey Research Center has likewise demonstrated the effects of differing conditions of organizational control on the involvement and satisfaction of employees within a business organization. ${ }^{2}$

The results of these studies emphasize the importance of control as a socialpsychological variable, especially for the understanding of organizations. There are a number of reasons for this importance. First of all, by definition, control is the capacity to manipulate available means for the satisfaction of needs (4). Control is basic to the distribution of rewards and punishments within the organization. What a person gets out of an organization depends in part on who controls the available stock of rewards within the organization, or, more generally, on who determines the way in which the organization shall operate. Control processes, of course, are an essential aspect of the functioning of an organization. They help circumscribe idiosyncratic individual actions and keep them conformant with the rational plan of the organization. Organizations require conformity and the integration of diverse processes. It is the function of control to see that organizational requirements are properly met, and the ultimate goals of the organization achieved.

Control has further social-psychological significance because of its association with types of political systems. Democracy is described as control by the citizens and their representatives. Dictatorship can be characterized as a highly centralized system of control, with ultimate power concentrated in one or a few persons. Oligarchy and laissez-faire, communism and fascism, refer to different systems of control, to the distribution of control among people in different social positions, and to the extent to which the behavior of an individual is subject to the control of others.

1. The authors would like to thank Angus Campbell, James K. Dent, Eugene Jacobson, and Daniel Katz for their helpful comments concerning this paper.

2. This work was begun under the general direction of Daniel Katz, and was directed by Nancy C. Morse and Everett Reimer. The authors would like to acknowledge this study in particular for laying the ground-work for many of the ideas discussed in the present article. For a brief relevant description of this project see N. C. Morse, E. Reimer, and A. S. Tannenbaum (5). 
Control, as a social-psychological variable, is important for another reason. Psychological predispositions to types of control systems are developed early in life. The infant's behavior is controlled by persons upon whom he is extremely dependent, and the process of socialization involves the imposition of controls by parents, teachers, and other 'authority figures'. In this growing-up process, a pattern of responses to control is developed. Control takes on an emotional meaning.

Control, then, is important as a variable because it relates to the satisfaction of important human needs, because it has broad social and political implications, and because it has acquired an emotional meaning for people. A very general notion upon which this investigation is based states that differences in control systems within organizations will make for numerous and widespread differences in the functioning of those organizations.

It is our objective in this paper to illustrate a descriptive technique for the study of organizational control structure. Although this method is largely in an exploratory stage, it nevertheless helps clarify certain aspects of control in organizations. It appears further to suggest new dimensions of importance.

The data represented below are taken from a study of membership participation in four local unions. The unions chosen for study are of the industrial type, are within a size range of 300-850 members, and are located in Michigan. They were chosen to differ in their level of membership participation as measured by attendance at meetings (regular and special), member activities at these meetings (such as raising and seconding motions, asking questions, etc.), involvement in committee work, and voting in union elections. The locals are assigned fictitious names, and are called, in the order of their level of membership participation: National, Sergeant, Ensign, and Walker. ${ }^{3}$

We shall be interested below in exploring the control characteristics of these locals as they relate to participation, and shall discuss tentatively the relationships among aspects of control, ideology, and uniformity behavior in unions.

\section{THE CONTROL GRAPH}

We have chosen to represent the control structure of our locals in terms of a general schema that we have called the 'control graph'. The horizontal axis of this graph represents a scale of hierarchical levels in an organization. In many local unions this scale would run from the rank-and-file members at the low end through various office levels to the president at the high end. (In a business organization, it might include the employees at one end; various supervisory groups at intermediate levels; and the board of directors, or president of the board, at the other end.)

The vertical axis of the control graph represents the amount of control instituted by these various hierarchical levels. This may vary from none to a very great deal of control. Thus, 'having a great deal of control' means that persons at the hierarchical level under consideration determine in large degree the specific actions and policies of the organization. 'Having no control' on this dimension means that all persons

3. Participation in the four locals was measured by means of a written questionnaire administered to a random sample of about 150 members in each local. The rank order of locals obtained in this way corresponds to independent judgment made by international officers. 
at a given level have no 'say' or influence in determining the policies and actions of the organization.

We can now create a curve by plotting and connecting the points that show the amount of control characteristic of each hierarchical level. One can conceive of such control curves assuming various shapes and levels. For example, one curve may have a negative slope, indicating that the amount of control instituted at successive levels increases as one goes up the hierarchy. Such a curve might be a relatively straight line, indicating regular increases in control from one level to the next (Figure 1), or it might have a positive or negative acceleration. In some organizations, there may be very little increase in the degree to which the various levels institute control until the top of the organization is reached; there a great increase takes place. This type of organization is controlled by only a few individuals (Figure 2). It is conceivable too, for the curve to decline as one moves up the hierarchy. An organization in which the leader has little power relative to the body politic would yield such a picture (Figure 3). A curve of this kind does not necessarily identify a figurehead or ineffective leader. This shape of curve applies also to an organization where individuals at the lower levels as a group have more control than the individuals at the uppermost level, even though these may be active and effective leaders.

Some organizations may be characterized by a relatively flat curve. Such a curve may be low and flat, indicating a very low degree of control throughout the organization. A laissez-faire or anarchic situation, for example, would be described in these terms (dotted line in Figure 4). On the other hand, a flat curve might be high on the vertical axis, indicating that people at all levels in the organization have a great deal of influence (solid line in Figure 4). The difference between these two flat curves, one low and one high, illustrates a general postulate concerning control curves, that the shape of the curve may remain constant while the general height of the curve varies. In other words, the relative power of different hierarchical levels might be the same in two organizations that nevertheless differed greatly in the absolute amounts of control exercised. Important differences in organizational functioning would be expected to accompany such variations in the general height of the control curve, despite the fact that the shape of the curves remained the same.

Control curves give us, by implication, a good deal of information about an organization. It can be seen from the preceding diagrams that the height and shape of the control curves tell us something about how control is distributed in an organization and also something about the total amount of control that is instituted in that organization. This latter dimension, total control, is indicated by the general height of the control curve, or more properly by the area under the curve. It is to a large degree independent of the shape of the curve. Total control may vary while the general shape of the curve remains the same. On the other hand, the general shape of the curve may vary while total control remains constant.

Data on total control, together with information on the distribution of control within the organization, should provide an effective method of describing important aspects of the control structure in an organization. For example, a high flat curve suggests that many persons in the organization have a lot of 'say' on many issues. A low flat curve indicates that no one has much to say about any issue. In the former we have the picture of an active, relatively strong organization eliciting the involvement and participation of a large segment of its members. The latter implies 


\section{Figures 1-4 \\ The Control Graph-Types of Control Curve}
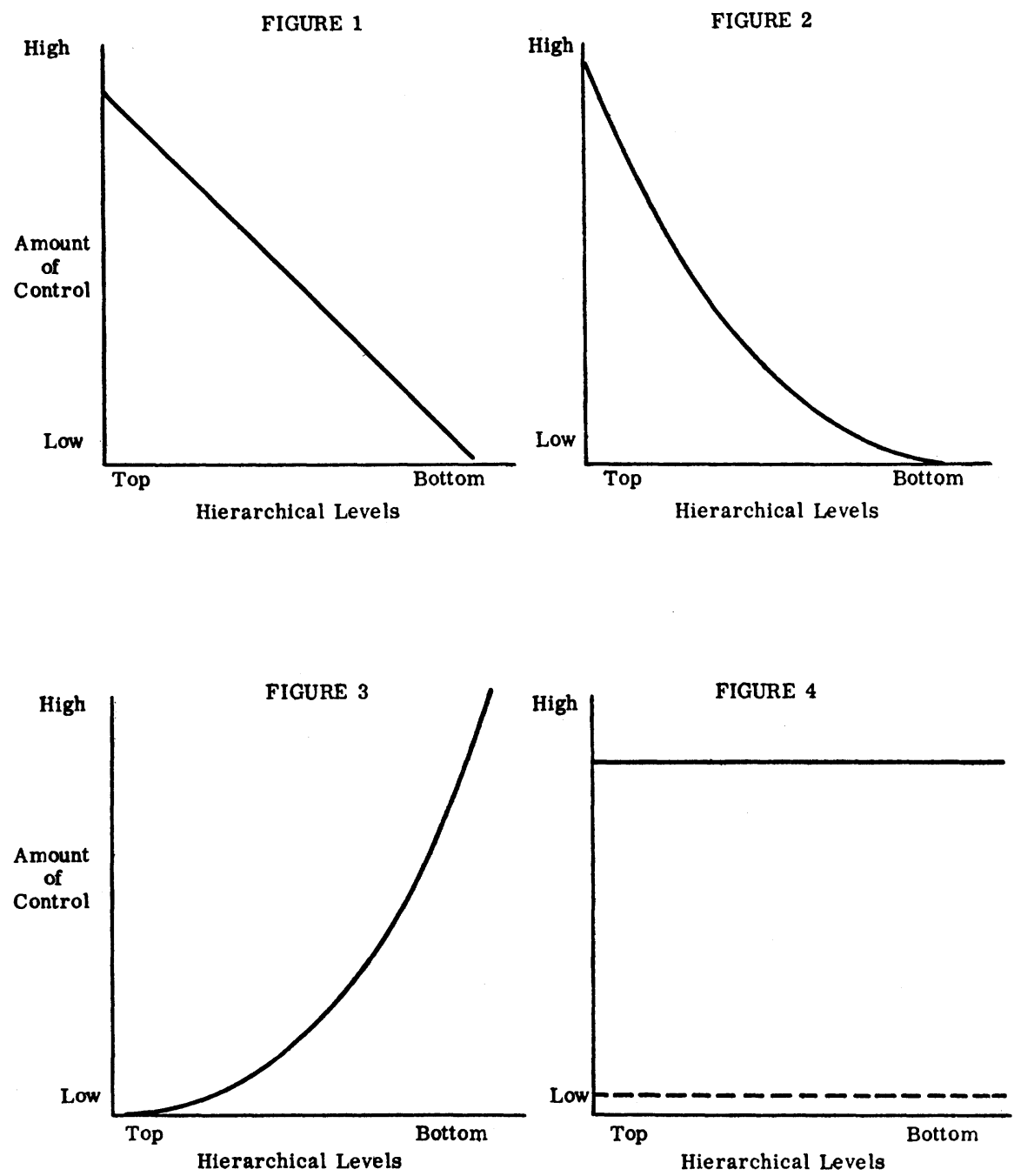
a relatively weak, inactive, laissez-faire organization. In the extreme case there is question as to whether or not the agglomeration of persons involved in such a situation can be called an organization at all.

In order to derive control curves for the locals studied in the present research, the amount of control instituted by individuals at varying levels in the union hierarchy was ascertained. The hierarchical levels include the membership at the low end, the president at the high end, and the executive board and bargaining committee somewhere between. ${ }^{4} \mathrm{We}$ have operationalized control at these various levels by asking judgments of our sample of respondents. This means, of course, that we are measuring control in terms of member-perceptions rather than by more objective means. We are making the assumption that an accurate picture of control in these locals can be derived as an average of all the members' judgments. The validity of this assumption remains to be tested fully, but in the present instance it received some confirmation from the observations of the authors and the judgments of international officers. The four questions employed in this connection are:

1. 'In general, how much do you think the president has to say about how things are decided in this local?'

2. 'In general, how much do you think the executive board has to say about how things are decided in this local?'

3. 'In general, how much do you think the plant bargaining committee has to say about how things are decided in this local?'

4. 'In general, how much do you think the membership has to say about how things are decided in this local?'

Each of these questions was answered by checks on a five-point scale ranging from 'a great deal of say' to 'no say at all'. Figure 5 represents the control curves for the four locals based on the data from the above questions.

A number of comparisons are possible from these curves (p. 132).

1. within-local differences in the extent to which various hierarchical levels exercise control,

2. between-local differences in the extent to which any given hierarchical level exercises control,

3. between-local differences in the general shape of the curves,

4. between-local differences in total control-the general height of the curves. ${ }^{5}$

In the following discussion, it will not be possible to explore in detail each of these potential lines of analysis. We will attempt, however, to include in our observations points illustrative of all four types of comparison.

An examination of the curves tells us immediately that within each local the several hierarchical levels appear to institute different amounts of control, although the differences are more marked in some locals than in others. In order to evaluate more precisely which of these visible differences represents significant increments of control, statistical tests were performed on the differences between the amount of

4. It is obvious that we are not dealing with equal scale units along the abscissa, and that the ordering of executive board and bargaining committee is somewhat arbitrary. While it is clear that these groups fall between the president and the membership, their relative positions are uncertain.

5. This is operationalized in the present study simply by adding the amount of control for all of the groups - the membership, executive board, etc.-in each local. 
FIGURE 5

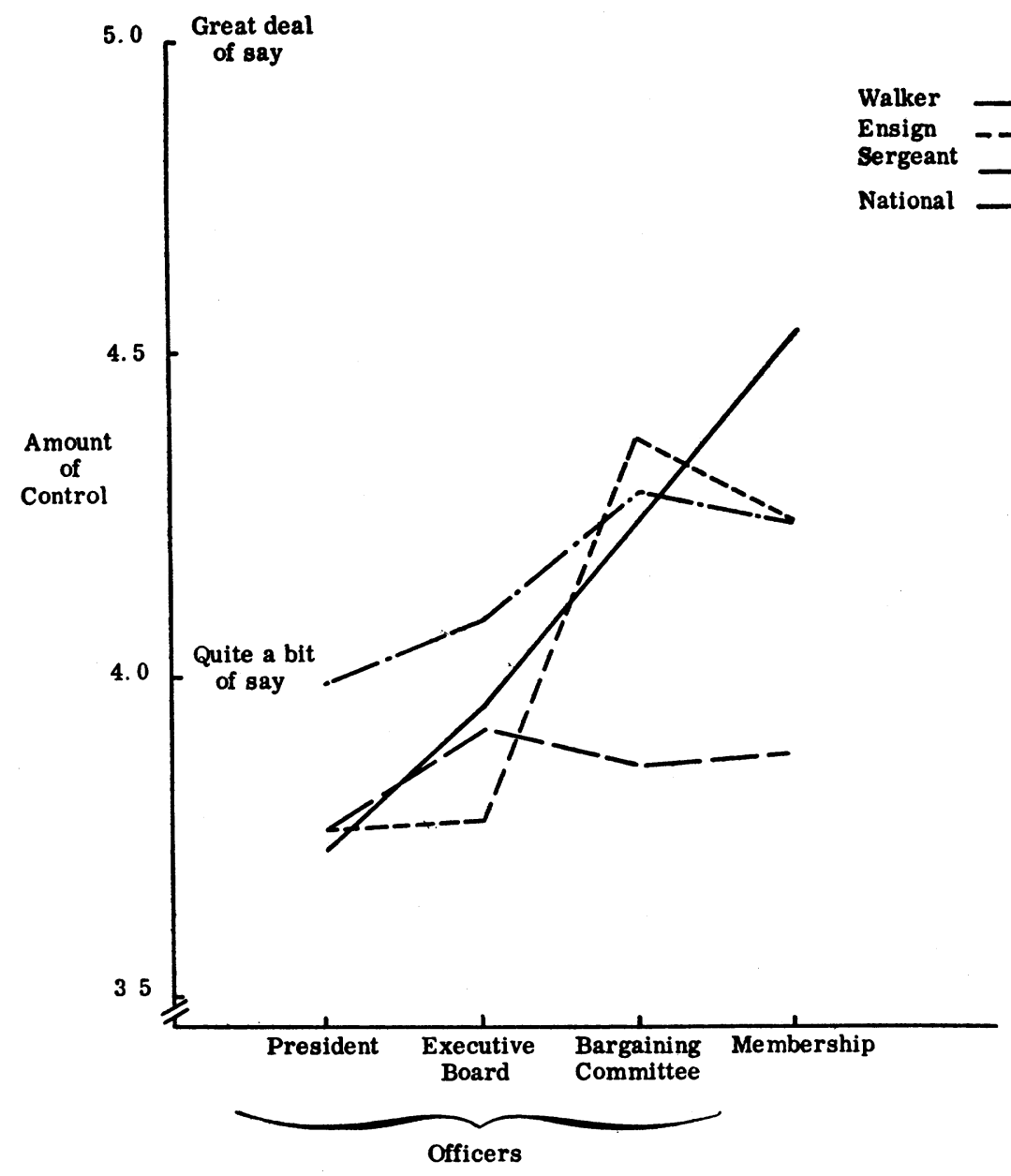

Hierarchical Levels

CONTROL CURVES OF FOUR UNION LOCALS BASED ON MEAN SCORES OF RATINGS ON HOW MUCH SAY VARIOUS PERSONS AND GROUPS HAVE IN HOW THINGS ARE DECIDED IN THE LOCAL *

* The means are based on N's of about 150 in each local. 
control exercised by the membership of a local and the amount exercised by each of the officer levels-president, executive board, and bargaining committee. In National, the membership as a whole has a significantly greater amount of control than either the bargaining committee, executive board, or the president. ${ }^{6}$ In Ensign, the membership as a whole is significantly higher than the executive board and the president, but does not differ significantly from the bargaining committee. In Walker, the membership does not differ significantly from any other group, but a suggestive difference exists between the membership as a whole and the president. In Sergeant, the membership is significantly higher than the president, but it does not differ from the other groups in the local.

An examination of the curves for between-local differences in the amount of control exercised by a given hierarchical level calls attention to some differences that offer corroboration of information obtained earlier by observation and from the comments of international officers. For example, the sharpest contrast between locals is that between the amount of control exercised by the membership in National, the local highest in member-participation, and that exercised in Walker, the local lowest in participation. National had been cited by international officers as a local in which the membership was especially active in decision-making.

A similar comparison can be made in terms of the amount of control exercised by local presidents. Sergeant stands out among the four locals as having the most influential president. This is substantiated by direct observation of this officer, by the reference of the international officers to his 'tight political machine', and by his election to seven successive terms of office. At the time of this measurement no other local president had served more than a year.

Comparisons in the shape and height of the four curves can be discussed simultaneously to some advantage. The curves for Walker and Sergeant are both relatively flat, but the amount of total control in these two locals differs sharply. Sergeant is high in total control, while Walker is relatively low. National stands out as having a relatively steep curve. It is the only local where no other group ranks above the membership in amount of control. In Ensign and Sergeant the bargaining committee ranks first and in Walker the executive board ranks first, although these within-local differences are not significant. While a definitive characterization of the four locals should not be attempted on the basis of these data alone, National appears to conform most closely to the 'democratic' model, while Walker more closely approximates the laissez-faire model. Sergeant's high total control with lower membership control suggests a kind of oligarchy or 'élite' government, while Ensign appears to conform least to previously discussed prototypes. ${ }^{7}$

Although the membership as a whole ranks high on the control curves, this does not imply that each member individually has more influence than each officer individually. The average member, though part of a group having a great deal of influence in the local, is very markedly less influential than the president, for example. The power of the membership is distributed among a large number of people; that of the president is in the possession of one person. Moreover, although

6. The t-test for paired differences was employed here. The 5 per cent level of confidence is accepted as a criterion of significance. Differences at between the 5 and 10 per cent levels are referred to as suggestive.

7. It should be remembered that these classifications are inferred from the curves and are not the basis for the curves. The essential element in our discussion is the curve itself and not the types associated with it. 
in one local the membership is the single most powerful group and in the other three the second most powerful group, the membership cannot be considered (except perhaps in National) to be more influential than the other groups combined. The above data seem to suggest that, while the membership does have very high influence in each of these locals, the officers (including the president, executive board, and bargaining committee) as a group might have more. Their influence would be dominant if the officers were to act in a concerted manner, as a single tight-knit group.

\section{THE APPLICATION OF CONTROL CURVES}

Many questions and hypotheses relating control to other functions in organizations have been proposed in the literature. For example, how does control relate to conformity behavior, to participation, to leadership characteristics, to the ideology or philosophy of an organization? What effects do such variables have on the control structure of an organization, and in what ways are they affected by that structure? The limited sample of four locals of course precludes any definitive answer to such questions; however, by way of illustrating the application of control graphs, a number of tentative conclusions are suggested. 8

The control graphs suggest that some current hypotheses about organizations might be sharpened if they were stated in terms of specific dimensions of control (such as its hierarchical distribution or the total amount of control instituted by all hierarchical levels), rather than in more global terms. For example, let us take a question around which conflicting hypotheses have been generated: what are the implications of inter-organizational conflict on control processes within the opposing organizations? One school of thought maintains that 'Continued ... antagonism between corporations and unions prevents the latter from sinking into bureaucratic sloth. Merely to survive, the union must remain vital, democratic and militant' (2). On the other hand, we have the widely held belief that conflict between organizations may lead to the tightening of control by the leadership.

The data of the present study suggest that conflict between organizations is related to the total amount of control exercised in these organizations, but not necessarily to the hierarchical distribution of that control (see Table 1, p. 135). The rank order of the four locals with respect to amount of conflict with management is identical with their rank order on total control, but apparently unrelated to the slope of the control curve (i.e. distribution of control). ${ }^{9}$

On the basis of these data, we might hypothesize that the most immediate effect of conflict with management is to increase the amount of control within the local. The rationale for this hypothesis might be developed along these lines: conflict does not necessarily imply who should exercise control, but merely that control should be exercised. Conflict increases the organizational problems implicit in idiosyncratic behavior. This may serve as an incentive for concentrating control in the hands of a few or for increasing the total amount of control in the organization in other ways. The important thing is that the organization be more tightly and 'efficiently'

8. A. Tannenbaum discusses more thoroughly the rationale and implications of the relationships sketched in this section in (7). See also a forthcoming book by the authors.

9. The ordering of locals with respect to union-management conflict was done a priori, on the basis of information obtained from company and union officers. 
controlled. During conflict (or certain other crises), there may be a greater sensitization to and acceptance of control throughout the organization, not merely at the lowermost levels. We are therefore led to the hypothesis that inter-organizational strife will create an increase in total control-but not necessarily exerted at the top of the organization. The distribution of this control in time of crisis is determined by other factors, as it is in more restful periods.

What factors do determine the distribution of control? One general view states that the specific external functions that the union performs have an important effect on how control is structured within the union. For example, Hoxie argues that 'business unions', which strive exclusively toward the achievement of such specific 'bread-and-butter' goals as higher wages, shorter hours, and pensions, tend to emphasize internal discipline and autocratic control (3). Howe and Widick make the complementary suggestion that unions that are interested in broader social functions and problems (political action, the general welfare of the community, organizing the unorganized) tend to be democratically controlled (2).

In the present study, members were questioned directly regarding their level of interest in eight different issues, each of which had been judged by the authors to represent either 'broad' or 'bread-and-butter' goals. Member-responses were combined to form indices of interest level in each type of goal. Evidence from these data, summarized in Table 1, lends some support to the hypothesis that an interest in broad and general goals for the union may be correlated with the observance of democratic procedures (positive sloped curve). However, interest on the part of the union in bread-and-butter issues does not appear to be correlated, positively or negatively, with democratic procedures. This no doubt reflects the fact that a union may have an interest in both types of goal; an interest in broad issues does not imply lack of interest in bread-and-butter problems.

A final example of the application of control curves can be given brief mention here, with a summary of the relevant data in Table 1 . This involves the phenomenon of conformity or uniformity of attitudes and behaviors in unions. Uniformity was measured in this study in terms of the inverse of the variance on a number of items chosen a priori to reflect union norms. These items include perceived norms about voting, attending meetings, and helping out on strikes; the frequency of sanctions against members for failure to perform the above functions; the intensity of memberinvolvement in the union, and the alacrity with which members utilize union channels for the expression of grievances. Uniformity, like inter-organizational conflict, appears to be associated with total amount of control, rather than with

TABLE 1 RANK ORDER OF LOCALS ON CERTAIN ASPECTS OF THEIR CONTROL STRUCTURE AND OTHER VARIABLES

\begin{tabular}{lcccccc} 
Local & $\begin{array}{c}\text { Degree of } \\
\text { positive } \\
\text { slope of } \\
\text { control } \\
\text { curve }\end{array}$ & $\begin{array}{c}\text { Subscription } \\
\text { of members } \\
\text { to broad } \\
\text { goals }\end{array}$ & $\begin{array}{c}\text { Total } \\
\text { amount } \\
\text { of } \\
\text { control }\end{array}$ & $\begin{array}{c}\text { Uniformity } \\
\text { behavior }\end{array}$ & $\begin{array}{c}\text { Extent of } \\
\text { manion- } \\
\text { conflict }\end{array}$ & $\begin{array}{c}\text { Subscription } \\
\text { of members } \\
\text { to bread- } \\
\text { and-butter } \\
\text { goals }\end{array}$ \\
\hline National & 1 & 1 & 2 & 2 & 2 & $2 \cdot 5$ \\
$\begin{array}{l}\text { Ensign } \\
\text { Sergeant }\end{array}$ & 2 & 3 & 3 & 3 & 3 & 4 \\
Walker & 3 & 2 & 1 & 1 & 1 & 1 \\
& 4 & 4 & 4 & 4 & 4 & $2 \cdot 5$ \\
\hline
\end{tabular}


the distribution of control within the local. Thus, in the present sample, greatest uniformity is found in Sergeant, which ranks first in total control; there is least uniformity in Walker, which ranks last.

\section{FURTHER IMPLICATIONS AND QUESTIONS}

The above discussion is intended to illustrate briefly the application of control curves to testing relationships between aspects of control and other organizational factors. Some further implications and questions relating to the use of these curves are summarized below.

1. The curves characterize in terms of two continuous variables a number of organizational types that have hitherto been treated as important but discrete. Such concepts as democracy, autocracy, and laissez-faire as distinct types or classes of control structure are brought into a single schema. We are thus provided with a unitary way of looking at these types, and at the same time working with the many variations between these extremes. A democratic control structure in unions might be diagrammed as a control curve having particular shape. This curve would be high for the rank-and-file and relatively low for persons in the upper hierarchy. The autocratic model, on the other hand, might present a somewhat different picture. This curve would be low for the rank-and-file and relatively high for those at the top of the hierarchy. Laissez-faire involves still another picture-one that is low for all levels of the hierarchy; no one has any appreciable control over the organization. The converse of laissez-faire would be described by means of a curve high at all points along the hierarchy. This would be a highly regulated type of organization, perhaps characterized by a large amount of internal political activity and clique-formation. Although such a control pattern would seem to be as interesting and important in its implications as laissez-faire, it has been neglected in social studies. Needless to say, the infinite variations between these extremes are also of interest; it seems likely that a full understanding of control in organizations will come, not alone through studies of democracy, autocracy, and laissez-faire as pure types, but through studies that examine the full range of control patterns in organizations.

2. The control curves of course emphasize the importance of control in organizations, and provide a means of taking a more holistic view of it. Studies of leadership, influence, and power in organizations can be made within such a framework. Leadership, for example, is not simply the influence of one isolated person by another, but a process in which the persons involved are placed at various points on the organizational control curve. It can be expected that such leadership processes and behaviors will be affected by the positions of the actors on this curve, and also by the general shape of the curve itself. Some research data already available point in this general direction. For example, Pelz finds that a leader is effective with his subordinates to the extent that the leader himself has influence in the organizational hierarchy (6).

Questions in this area that deserve further investigation include the following: What effect does varying the relative power positions of leaders and followers have on leadership processes? What implications do varying shapes of control curves have on leader-follower behavior? Is there an optimum curve for achieving maximum leadership effectiveness, and for other criteria of organizational functioning? 
Is the supervisor in an organization high in total control confronted by a set of role requirements different from those of the supervisor in an organization that is relatively low in total control?

3 . The control curve presents a picture of the control distribution in an organization. Organizational control, however, is a more fluid and dynamic process than is suggested by the control curves, which reflect the situation at a given point in time. The question of alignments and coalitions is one that should be considered. For example, one group may be lower than another in the amount of control it can institute in the organization, but it might add to its effective control by aligning with a third group. Groups might do this on a temporary basis relative to a specific issue, or they might form a more permanent faction or clique. If some rough assumptions about the additive properties of control can be tentatively accepted, certain judgments about the effects of various types of alignments might be made. For example, in an organization with an extremely steep curve, one group may be so powerful that no combination of opposing groups can overpower it. In an organization with a relatively flat curve the balance of power may be so delicate that any shift in the alignment of sub-groups may change radically the control situation. Such an approach leads into the intricate question of political processes in organizations, and suggests that an investigation of such processes could be carried out with the use of control curves.

4. One might speculate about the psychology of control in connection with these curves. One analysis of interest would entail plotting the control curves for all the organizations to which a given individual belongs: his work, his social groups, his family, etc. From this we can derive a control profile for the individual. These profiles can be expected to vary considerably from person to person, with some rather extreme types being manifest. One, for example, would be the individual who has relatively little control in any of the organizations to which he belongs. Another, and perhaps more rare type, is the individual who has relatively high control in all of the organizations to which he belongs. Still others will have differing degrees of control in the various types of organizations and groups to which they belong. An analysis of the psychological correlates of such differing patterns of control for individuals should be extremely rewarding. Their entire psychology, their way of looking at life, their general attitudes, their aspirations and levels of satisfaction would be expected to differ markedly. 10

5. There are, of course, many questions with regard to the use of the control curves as an analytical technique. These refer to methodological as well as theoretical difficulties:

(a) The units of measurement are problematical. Scaling of equal units along both the abscissa and ordinate would be ideal. This has not as yet been done, and is complicated by the fact that organizational hierarchies do not conform to simple statistical assumptions.

(b) The relationship between the actual control structure of an organization and the structure as perceived by its members and leaders requires further exploration. An accurate measure of the actual control structure is by far the more difficult to

10. The data of the present research suggest the hypothesis that active union members differ from inactive members on this control profile; actives tending more in the direction of greater control in the organizations to which they belong, while inactives tend in the direction of lower control. 
obtain. Although we have assumed that the measures employed in the present study accurately reflect the control picture as it actually exists, we recognize the need to test this assumption.

(c) There are aspects of control in organizations that appear to have broad implications, but are not fully reflected in the control graphs as they are presently drawn. The graphs do not give information about the mechanisms by which control is exercised, although these may modify greatly the effects of a given level or amount of control. For example, control may be exercised through the dispensation of rewards, the institution of sanctions, or through combinations of these. In organizations and political systems, control may be exercised directly, or indirectly through the employment of agents or representatives. While the graphs are designed to describe the amount of control that individuals at various hierarchical levels exercise, they do not describe the means through which this control is exercised.

(d) These curves may be better diagrammed in terms of specific areas of control rather than in terms of general (global) control in the organization. If specific areas are used, a satisfactory way of integrating these to provide an overall picture must be developed.

(e) The curves discussed above are based on what we have called active control. The actor is doing the controlling. Curves can also be drawn in terms of passive control. In these cases the actor is being controlled. The relationship between these two types of control needs further investigation. It would be informative in examining the control structure of an organization to consider simultaneously the passive control curve (the extent to which persons at various levels in the hierarchy are controlled) and the active control curve (the extent to which they are doing the controlling). An infinite number of variations are possible but a number of prototypes might be chosen for special study. For example, is the autocratic model one where active control is great at the top of an organization and small at the lower levels, and where the slope of the passive control curve presents the reverse picture?

Does the democratic model imply a reversal of the above curves? Is 'responsible leadership' distinguished from 'autocratic leadership' by the fact that the former has both high active and passive control? Is the 'responsible' leader, in other words, controlled as well as controlling? The president of a republic, for example, has considerable power (active control) but in turn he is also subject to many constraints (passive control). The leader in a dictatorship, on the other hand, may have a great deal of power, but relatively few constraints. The implications of the various shapes of active and passive control curves and the combinations of such' curves deserve further investigation.

(f) A type of hypothetical curve might be plotted describing the amount of control and the distribution of control that is desired by the membership. This may or may not correspond to the actual control structure. If these two curves, actual and desired, were superimposed, the discrepancies between them (perhaps best thought of in terms of the area between them) would be expected to have an important bearing on membership participation, involvement, and loyalty to the organization. In an organization where the actual control curve differs sharply from the desired curve, the area between these curves is great, and we would predict a corresponding degree of dissatisfaction, frustration, and disaffection among the members. Contrast this with a second hypothetical organization having the same actual control structure but in which the desired control curve corresponds more closely to the actual 
curve. We would predict for this organization a greater degree of membership satisfaction and loyalty.

We have only begun to think about this problem, but past psychological research suggests the importance of discrepancies between what individuals want and what they get. Although the actual distribution of control appears to have direct implications for the satisfaction of members, the difference between the actual and desired curves may make an additional contribution to our understanding of the implications of control.

While the control graph is primarily descriptive, it has both conceptual and operational advantages. It helps one think about the process of control and it offers specific operational indices for characterizing and measuring aspects of control in organizations. It opens up to the process of scientific testing a number of hypotheses that have been discussed primarily in speculative terms.

\section{REFERENCES}

1. Cartwright, Dorwin. 'Toward a Social Psychology of Groups.' Presidential address delivered before the Society for the Psychological Study of Social Issues, Cleveland, Ohio, 5 September 1953.

2. Howe, IRving, and WIDICK, B. J. The UAW and Walter Reuther. New York: Random House, 1949.

3. HoxIE, R. F. Trade Unionism in the United States. (2nd ed.) New York: Appleton, 1923.

4. KNICKerbocker, I. 'Leadership: a Conception and Some Implications.' J. soc. Issues, Vol. IV, pp. 23-40, Summer 1948.

5. Morse, N. C., Reimer, E., and Tannenbaum, A. S. 'Regulation and Control in Hierarchical Organizations.' J. soc. Issues, Vol. VII, No. 3, pp. 41-8, 1951.

6. Pelz, Donald C. 'Leadership within a Hierarchical Organization.' J. soc. Issues, Vol. VII, No. 3, pp. 49-55, 1951.

7. Tannenbaum, A. S. 'Control Structure and Union Functions.' Amer. J. Sociol., Vol. LXI, No. 6, pp. 536-45, May 1956.

8. Worthy, James C. 'Factors Influencing Employee Morale.' Harv. Busin. Rev., Vol. XXVIII, pp. 61-73, January 1950.

\section{BIOGRAPHICAL NOTES}

Arnold Tannenbaum is a Study Director in the Human Relations Program of the Survey Research Center. He received his Ph.D. in psychology in 1954 at Syracuse University. He has recently directed the study of participation in four local unions upon which the present article is based and is presently completing a book with Robert Kahn describing the results of this project.

Robert L. KAHN is the Director of the Human Relations Program of the Survey Research Center, University of Michigan. He received the B.A., M.A., and Ph.D. degrees from that university. After leaving the university in 1940, Mr. Kahn taught for two years in the Detroit secondary schools, and then became state supervisor of a series of studies of manpower, housing, and related problems. Late in 1942 he 
went to the Bureau of the Census in Washington as a research analyst. In subsequent years he held several other positions in the Bureau, and became acting chief of its Field Division, directing the large-scale collection of data by interview and questionnaire.

Since 1948, Mr. Kahn has been at the Survey Research Center. There he has directed research on economic and political behavior, and on problems of organizational structure, supervisory practices, productivity, and morale. Among his publications are The People Elect a President (written with Angus Campbell), Human Organizations and Worker Motivation, Some Recent Findings in Human Relations Research (written with Daniel Katz), and Morale and Productivity. 